\title{
A Comparison of Modeled and Measured Surface Shortwave Irradiance for a Molecular Atmosphere
}

\author{
S. Kato* and T. P. Ackerman \\ Department of Meteorology \\ The Pennsylvania State University \\ University Park, Pennsylvania \\ *Now at Hampton University \\ Hampton, Virginia \\ E. G. Dutton \\ NOAA-Climate Monitoring and Diagnostics Laboratory \\ Boulder, Colorado \\ $N$. Laulainen and N. Larson \\ Pacific Northwest National Laboratory \\ Richland, Washington
}

\section{Introduction}

There is a growing body of evidence that models overestimate clear-sky downward shortwave surface irradiances (Charlock and Alberta 1996, Kato et al. 1997, Kinne et at. 1997, Wild et al. 1981). Kato et al. (1997) showed that their model, with the best available gaseous absorption cross section data, accurately computes direct irradiance provided that the model has as input accurate water vapor and ozone profiles and extinction optical thickness of the atmosphere at a set of discrete wavelengths. However, the overestimate of the downward diffuse irradiance by their model is significant; the difference is largest near $400 \mathrm{~nm}$ and decreases with increasing wavelength. The two-stream approximation, which was used in their study, has a reported accuracy of better than $10 \%$ when computing the diffuse irradiance of a molecular atmosphere, based on comparisons with more sophisticated models (Toon et al. 1989). Our goal in this paper is to determine the agreement between the modeled and measured downward diffuse irradiance and to enhance our confidence level in our model calculations and measurements for a molecular atmosphere.

\section{Radiation Data}

We measured the direct normal and diffuse irradiance at the Mauna Loa Observatory (latitude, 19.54N; longitude, 155.58W; elevation, $3397 \mathrm{~m}$ ) operated by the National Oceanic and Atmospheric Administration (NOAA) Climate Monitoring and Diagnostics Laboratory (CMDL).
The direct normal irradiance was measured by a pyrheliometer and the downward diffuse irradiance by a shaded pyranometer. The pyrheliometer is calibrated once a month against a cavity radiometer. Once every two years, all radiometers are calibrated at the NOAA CMDL solar calibration facility. Based on our experience with these instruments, we estimate that the uncertainty in the measured direct normal irradiance is $1 \%$ and the uncertainty in the downward diffuse irradiance is $5 \mathrm{Wm}^{-2}$ to $6 \mathrm{Wm}^{-2}$, which corresponds to approximately $10 \%$ of the downward diffuse irradiance under clear-sky conditions at the observatory.

Based on the shortwave extinction optical thickness measured by a multifilter rotating shadowband radiometer (MFRSR) (Harrison et al. 1994) over 2 years, we selected 6 clear-sky days that were cloudless and had very small aerosol loading, i.e., that were a nearly molecular atmosphere (Table 1). We limit our comparisons to the mornings because the aerosol optical thickness tends to increase in the afternoon because of an upslope wind from the coastal areas of the island.

\section{Model and Its Input Data}

Our two-stream radiative transfer model is based on the numerical algorithm introduced by Toon et al. (1989). We use $k$-distributions and the correlated- $k$ approximation and incorporate gaseous absorption by water vapor, including continuum absorption, ozone, oxygen and carbon dioxide into the model (Kato et al. 1998). We obtained water vapor 


\begin{tabular}{|l|c|c||}
\hline \hline \multicolumn{3}{|c|}{$\begin{array}{c}\text { Table 1. Column water vapor and aerosol optical } \\
\text { thickness at 477 nm for the selected days. }\end{array}$} \\
\hline \multicolumn{1}{|c|}{ Date } & $\begin{array}{c}\text { Aerosol Optical } \\
\text { Thickness at } \\
\mathbf{4 7 7} \mathbf{~ n m}\end{array}$ & $\begin{array}{c}\text { Column Water } \\
\text { Vapor } \text { gcm }^{-2}\end{array}$ \\
\hline August 5, 1995 & 0.007 & 0.49 \\
\hline August 6, 1995 & 0.005 & 0.36 \\
\hline August 8, 1995 & 0.006 & 0.35 \\
\hline August 16, 1995 & 0.008 & 0.38 \\
\hline January 7,1996 & 0.003 & 0.36 \\
\hline January 15,1996 & 0.005 & 0.42 \\
\hline
\end{tabular}

profiles from soundings launched from Hilo, Hawaii, at 00 UT (the local time is 10 hours behind Universal Time). We incorporated surface observations of pressure, temperature, and relative humidity acquired at the Mauna Loa Observatory into atmospheric profiles obtained from soundings. We used values from the tropical standard atmosphere (McClatchey et al. 1972) to extend profiles above the level at which the soundings were terminated. The observed column ozone amount averaged over a month is 262 DU and 245 DU for August 1995 and January 1996, respectively. Because these values are close to the column ozone amount of the tropical standard atmosphere (McClatchey et al. 1972), we used the tropical standard ozone profile terminated at the level of the measured surface pressure of the observatory. The resulting column ozone amount is 240 DU. The total number of model layers used for the computation was 28 , and we estimate the surface albedo to be $0.055 \pm 0.015$ at the observatory under clearsky conditions.

\section{Results}

The absolute difference between the modeled and measured downward diffuse irradiance is less than $5 \mathrm{Wm}^{-2}$ (Figure 1); the fractional difference is within $10 \%$ of the computed downward diffuse irradiance for the molecular atmosphere, which is the estimated measurement uncertainty. The difference depends on time, especially on 5,8 , and 16 August, which may be caused by changes in the aerosol loading with time, changes in the orientation of the sun to the site geometry, or characteristics of the instrument. Because the aerosol optical thickness on these days is less than 0.01 at a wavelength of $477 \mathrm{~nm}$, the difference between the computational result with and without aerosol is within the uncertainty of the measurement (Figure 1). Since the uncertainty of the surface albedo is small, the uncertainty in the irradiance due to this is also small. Increasing or decreasing the surface albedo by 0.015 alters the downward diffuse irradiance by less than $1 \mathrm{Wm}^{-2}$.
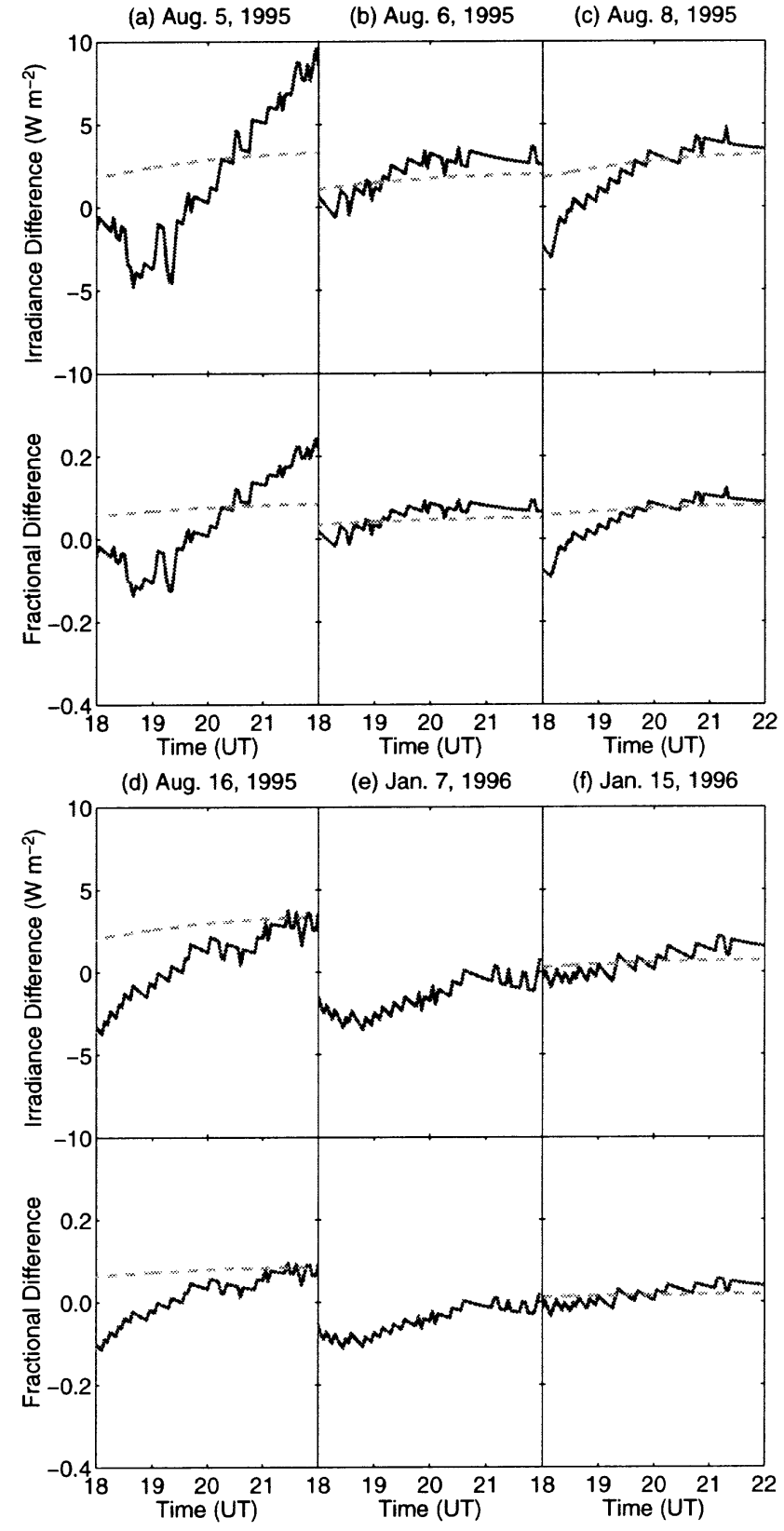

Figure 1. The difference of measured downward diffuse irradiance from the modeled downward diffuse irradiance for a molecular atmosphere (solid line). The dashed line indicates the difference of the modeled downward diffuse irradiance including a sulfate aerosol relative to those for the molecular atmosphere. We did not compute the diffuse irradiance including aerosol for January 7,1997 . The local time is 10 hours behind Universal Time. 
The absolute difference between the modeled and measured direct normal irradiance is slightly larger (Figure 2). The fractional difference of the direct normal irradiance is as large as $5.0 \%$, which corresponds to $54 \mathrm{Wm}^{-2}$. We speculate that the error in the water vapor amount in the model is the major source of the difference. Our sensitivity study shows that increasing the water vapor amount from $0.23 \mathrm{~g} \mathrm{~cm}^{-2}$ to $0.86 \mathrm{~g} \mathrm{~cm}^{-2}$ reduces the direct normal irradiance by $42 \mathrm{Wm}^{-2}$.

To eliminate the effect of the radiometer calibration constant, we compared the modeled diffuse-total ratio, which is defined as the downward diffuse irradiance divided by the downward total irradiance, with that measured by the MFRSR (Figure 3). We computed irradiances by neglecting gaseous absorption in the 10 -nm wide wavelength intervals of the MFRSR. The measured diffuse-total ratio falls in between the modeled diffuse-total ratio with and without aerosol for the 412-nm and 477-nm channels. However, the model slightly underestimates the diffuse-total ratio in the 776-nm channel. Because the diffuse irradiance is less than $3 \%$ of the total irradiance in these wavelengths (Figure 3), this may be a limitation of the instrument or due to an error involved in the correction process of over-shading by the shadow arm.

\section{Discussion and Conclusions}

Given the surface pressure, we can compute the molecular scattering optical thickness accurately (Young 1981) by using the hydrostatic approximation. While non-hydrostatic acoustic and buoyancy waves affect the approximation, the departure from the hydrostatic balance by these waves is well below $1 \%$. In addition, their influence on the surface pressure measurement is reduced by the slow response time of a typical barometer. The formula used to compute the molecular scattering optical thickness in this study is taken from Hansen and Travis (1974).

In a strict sense, a disagreement between the modeled and measured direct normal irradiance causes a difference in the source of the diffuse irradiance if the difference in the direct normal irradiance is caused by scattering. Because we know the molecular scattering optical thickness accurately and the atmosphere is a nearly molecular atmosphere, any difference in the direct normal irradiance is actually caused by absorption. Given the fact that spectral regions of known strong gaseous absorption in the atmosphere coincide with regions of small molecular scattering cross sections, the source of the diffuse irradiance is almost independent of the
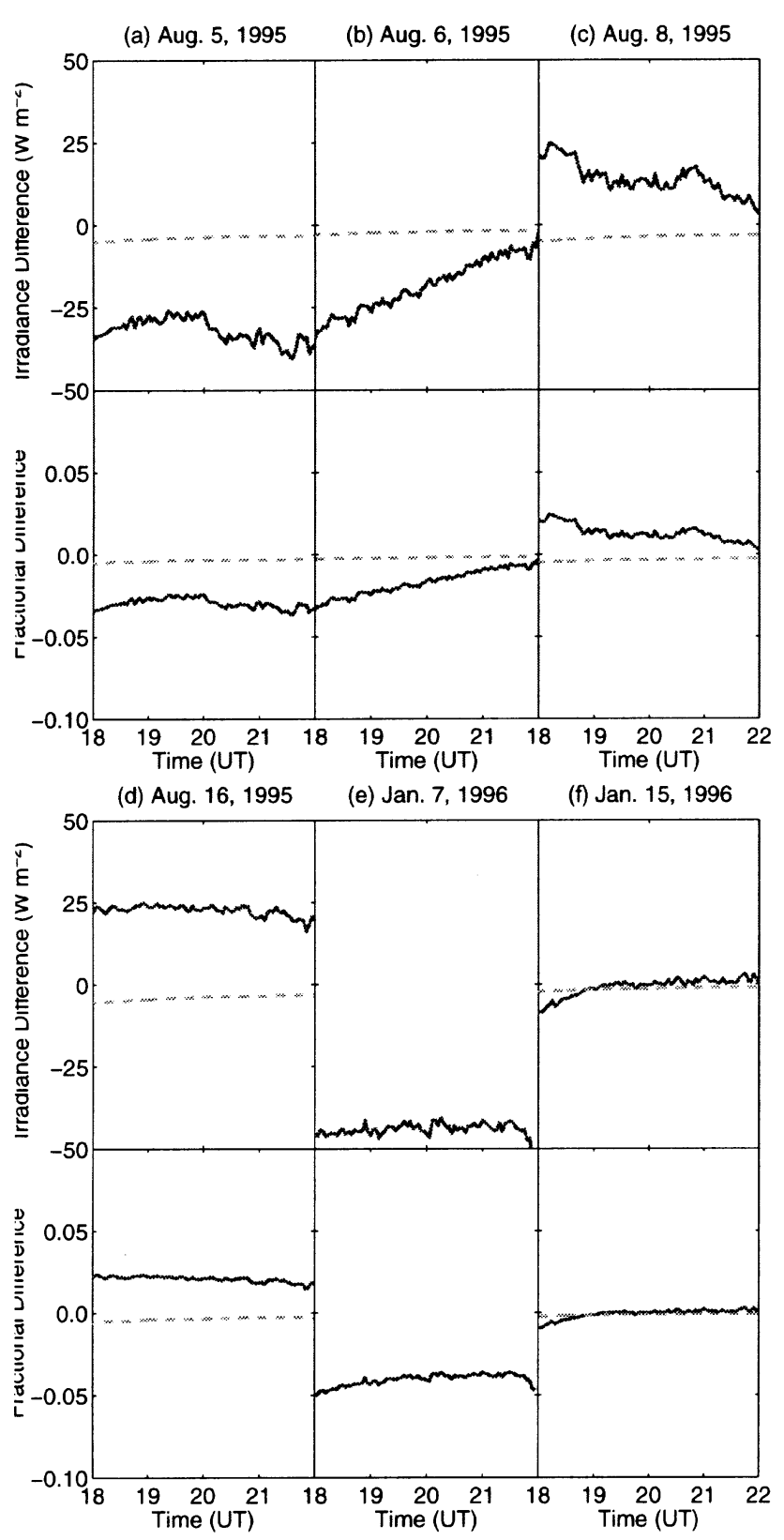

Figure 2. The difference of measured direct normal irradiance from the modeled direct normal irradiance for a molecular atmosphere (solid line). The dashed line indicates the difference of the modeled direct normal irradiance including an aerosol relative to those for the molecular atmosphere. We did not compute the diffuse irradiance including aerosol for January 7 , 1997. 


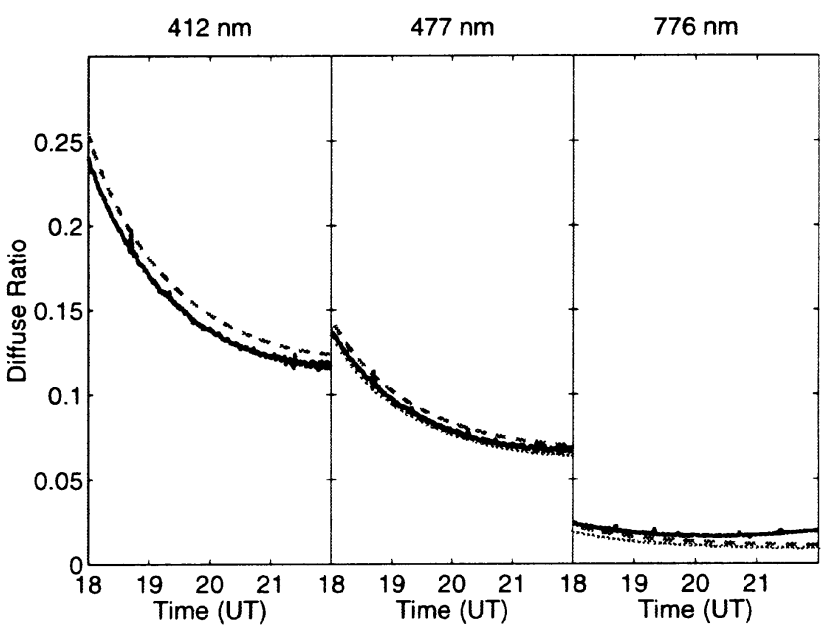

Figure 3. The diffuse-total ratio as measured by a multi-filter rotating shadowband radiometer (solid line). The dashed and dotted lines indicate the modeled diffuse-total ratios with and without a sulfate aerosol. The measured diffuse-total ratio coincides with the modeled ratio of molecular atmosphere for the 412-nm channel.

magnitude of the gaseous absorption. For example, doubling the water vapor amount has very little effect on the downward diffuse irradiance. Consequently, any differences in the direct normal irradiances are due to absorption, while any differences in the downward diffuse irradiances are due to scattering. Therefore, the result of the comparison of the downward diffuse irradiance is independent of that of the direct normal irradiance. In conclusion, this result indicates that the two-stream approximation on which the radiative transfer model is based is adequate for the diffuse irradiance computation for a molecular atmosphere.

\section{Acknowledgments}

We thank the Mauna Loa Observatory staff for maintaining the ongoing observations. We thank Drs. P. R. Bannon and C. F. Bohren for useful advice and Drs. E. E. Clothiaux, B. W. Forgan, L. Harrison, S. Kinne, and J. H. Mather for stimulating discussions.

\section{References}

Charlock, T. P., and T. L. Alberta, 1996: The CERES/ARM/GEWEX experiment (CAGEX) for the retrieval of radiative fluxes with satellite data. Bull. Am. Meteorol. Soc., 77, 2673-2683.

Hansen, J. E., and L. D. Travis, 1974: Light scattering in planetary atmospheres. Space Sci. Rev., 16, 527-610.

Harrison, L., J. Michalsky, and J. Berndt, 1994: Automated multifilter rotating shadow-band radiometer: an instrument for optical depth and radiation measurements. Appl. Opt., 22, 5118-5125.

Kato, S., T. P. Ackerman, E. E. Clothiaux, J. H. Mather, G. G. Mace, M. L. Wesely, F. Murcray, and J. Michalsky, 1997: Uncertainties in modeled and measured clear-sky surface shortwave irradiances. J. Geophys. Res., 102, 25,881-25,898.

Kinne, S, R. Bergstrom, O. B. Toon, S. Kato, T. P. Ackerman, E. Dutton, M. Shlobara, Y. Takano, A. Buchholz, and F. P. J. Valero, 1997: Clear sky atmospheric solar transmission a modeling in-depth analysis based on FIRE-91 field experiment data. Ninth Conference on Atmospheric Radiation, Long Beach, California.

McClatchey, R. A., R. W. Fenn, J. E. A. Selby, F. E. Volz, and J. S. Garing, 1972: Optical properties of the atmosphere, third edition. Environ Res. Pap. 411, Air Force Cambridge Res. Lab., Bedford, Massachusetts.

Toon, O. B., C. P. Mckay, and T. P. Ackerman, 1989: Rapid calculation of radiative heating rates and photodissociation rates in inhomogeneous multiple scattering atmosphere. J. Geophys. Res., 94, 16,287-16,301.

Wild, M., A. Ohmura, H. Gilgen, and E. Roeckner, 1981: Validation of general circulation model radiative fluxes using surface observations. J. Clim., 8, 1309-1324.

Young, A. T., 1981: On the Rayleigh-scattering optical depth of the atmosphere. J. Appl. Meteorol., 20, 328-330.

\section{Other Publications in Progress}

Kato, S., T. P. Ackerman, J. H. Mather, and E. E. Clothiaux, 1998: The $k$-distribution method and correlated- $k$ approximation for a shortwave radiative transfer model. J. Quant. Spectrosc. Radiat. Transfer, submitted. 